\title{
Progressive resistance training in head and neck cancer patients undergoing concomitant chemoradiotherapy
}

Lonkvist, Camilla K; Vinther, Anders; Zerahn, Bo; Rosenbom, Eva; Deshmukh, Atul S;

Hojman, Pernille; Gehl, Julie

Published in:

Laryngoscope Investigative Otolaryngology

DOI:

10.1002/lio2.88

Publication date:

2017

Document version

Publisher's PDF, also known as Version of record

Document license:

CC BY-NC-ND

Citation for published version (APA):

Lonkvist, C. K., Vinther, A., Zerahn, B., Rosenbom, E., Deshmukh, A. S., Hojman, P., \& Gehl, J. (2017).

Progressive resistance training in head and neck cancer patients undergoing concomitant chemoradiotherapy.

Laryngoscope Investigative Otolaryngology, 2(5), 295-306. https://doi.org/10.1002/lio2.88 


\title{
Progressive Resistance Training in Head and Neck Cancer Patients Undergoing Concomitant Chemoradiotherapy
}

\author{
Camilla K. Lonkvist, MD; Anders Vinther, PhD; Bo Zerahn, MD; Eva Rosenbom, RD; \\ Atul S. Deshmukh, PhD; Pernille Hojman, PhD; Julie Gehl, MD, DMSc (D)
}

\begin{abstract}
Objectives: Patients with head and neck squamous cell carcinoma undergoing concomitant chemoradiotherapy (CCRT) frequently experience weight loss, especially loss of lean body mass (LBM), and reduced functional performance. This study investigated whether a 12-week hospital-based progressive resistance training (PRT) program during CCRT is feasible in the clinical setting before planning initiation of a larger randomized study which is the long-term goal.

Study design: Prospective pilot study.

Methods: Twelve patients receiving CCRT were planned to attend a 12-week PRT program. Primary endpoint was feasibility measured as attendance to training sessions. Secondary endpoints included changes in functional performance, muscle strength, and body composition measured by Dual-energy X-ray Absorptiometry (DXA) scans. Furthermore, sarcomeric protein content, pentose phosphate pathway (PPP) activity, and glycolysis were determined in muscle biopsies.

Results: Twelve patients with p16 positive oropharyngeal cancer were enrolled. The primary endpoint was met with 9 of the 12 patients completing at least 25 of 36 planned training sessions. The mean attendance rate was $77 \%$. Functional performance was maintained during the treatment period and increased during follow-up $(p<0.01)$. Strength was regained after an initial dip during treatment, paralleling responses in LBM and sarcomeric protein content. LBM began to increase immediately after treatment. The PPP was upregulated after the treatment period, whilst glycolysis remained unchanged. No adverse events were related to PRT and in questionnaires, patients emphasized the social and psychological benefits of attendance.

Conclusion: Progressive resistance training is feasible and safe during CCRT for head and neck cancer, and is associated with high patient satisfaction.

Key Words: Head and neck cancer, progressive resistance training, exercise, body composition, lean body mass.

Level of Evidence: $2 \mathrm{C}$.
\end{abstract}

\section{INTRODUCTION}

Patients with head and neck squamous cell carcinoma (HNSCC) often experience unintentional weight loss during concomitant chemoradiotherapy (CCRT). ${ }^{1-3}$ Studies have shown that up to $72 \%$ of this treatmentrelated loss of body weight is due to loss of lean body

This is an open access article under the terms of the Creative Commons Attribution-NonCommercial-NoDerivs License, which permits use and distribution in any medium, provided the original work is properly cited, the use is non-commercial and no modifications or adaptations are made.

Additional Supporting Information may be found in the online version of this article.

From the Department of Oncology (C.K.L, J.G.), Department of Rehabilitation (A.V.), Department of Clinical Physiology and Nuclear Medicine (B.Z.), and the Nutritional Research Unit (E.R.), Herlev and Gentofte Hospital, University of Copenhagen, Herlev, Denmark; the Proteomics Program (A.S.D.), Novo Nordisk Foundation Center for Protein Research, Faculty of Health and Medical Sciences, University of Copenhagen, Copenhagen, Denmark; and the Centre of Inflammation and Metabolism and Centre for Physical Activity Research (P.H.), Rigshospitalet, University of Copenhagen, Copenhagen, Denmark.

Editor's Note: This Manuscript was accepted for publication 12 June 2017.

Financial disclosure: The study was supported by grants from TrygFonden, The Danish Cancer Society (R90-A5865-14-S2), and Krista og Viggo Petersens Fond. The sponsors had no influence on study design, collection, analysis, or interpretation of data

Conflict of interest: The authors report no conflict of interest.

Send correspondence to Julie Gehl, Department of Oncology, Herlev and Gentofte Hospital, University of Copenhagen, Herlev Ringvej 75, 2730 Herlev. E-mail: Karen.Julie.Gehl@regionh.dk

DOI: 10.1002/lio2.88 mass (LBM). ${ }^{1,4}$ which again is associated with decline of functional performance, ${ }^{4}$ quality of life (QoL), ${ }^{5}$ as well as increased morbidity and mortality. ${ }^{6-10}$ Loss of LBM and body weight can occur even when caloric intake is sufficient to meet energy demand, ${ }^{11}$ indicating a multifactorial pathogenesis.

Epidemiologic studies show that in addition to improving physical functioning, physical activity is associated with reduced risk of several cancers ${ }^{12}$ and reduced mortality. ${ }^{13,14} \mathrm{~A}$ direct effect of exercise suppressing cancer growth has been shown in preclinical studies, pointing to an exercise-dependent regulation of tumor biology. ${ }^{15,16}$

Furthermore, studies indicate that chemotherapy side effects may be ameliorated by exercise. In a preclinical study using weekly cisplatin, exercise attenuated treatment-induced weight loss and increased muscle mass, compared with controls. ${ }^{17}$

In head and neck cancer patients, exercise trials studying training intervention during radiotherapy or CCRT are sparse but have been gaining ground and some studies have been published whilst this study was conducted. ${ }^{18-21}$ The trials all differ in type of intervention, intensity, frequency, as well as outcome measures. But across these studies, changes in muscle strength, mobility, physical activity, fatigue, diet, and QoL endpoints in favor of the training intervention group are reported. 
Resistance training is an efficient way of maintaining or increasing muscle mass and the aim of this pilot study was to test the feasibility of a 12 -week PRT program, as well as the entire study logistics with scans, questionnaires, and controls in our clinic before launching a randomized trial with difference in LBM as primary outcome measure.

We hypothesized that although HNSCC patients experience a large symptom-burden during treatment, PRT would be a feasible intervention during CCRT. Secondary aims were to investigate whether PRT may ameliorate weight loss and loss of LBM, as well as maintain muscle strength and functional performance in HNSCC patients. The chosen setting was a single-arm intervention study comprising hospital-based supervised PRT for 12 weeks during and immediately after CCRT for patients with HNSCC.

\section{MATERIALS AND METHODS}

\section{Study Design and Patients}

The study was a single-center, prospective study registered at www.clinicaltrials.gov (NCT02068950), and approved by the regional Ethics Committee (\# H-3-2013-186) and the Danish Data Protection Agency.

Inclusion criteria: 1) histologically verified primary HNSCC with primary tumor in the nasal cavity, oral cavity, pharynx, or larynx, stage III or IV, and candidate for CCRT according to the Danish Head and Neck Cancer (DAHANCA) group guidelines; 2) Eastern Cooperative Oncology Group (ECOG) performance status (PS) $0-1$; 3) age $\geq 18$ years; and 4) signed informed consent.

Exclusion criteria: 1) comorbidity potentially interfering with attendance or test results; 2) tonsillectomy within a week before inclusion; 3) psychological, social, or geographical conditions that could influence protocol adherence; 4) diastolic blood pressure $<45$ or $>95$, resting heart rate $>100$; 5) signs of ischemia on electrocardiogram; 6 ) insufficient bone marrow function (i.e., hemoglobin $<6 \mathrm{mmol} / \mathrm{L}$, leukocytes $<2.5 \times 10^{9} / \mathrm{L}$, or platelets $\left.<50 \times 10^{9} / \mathrm{L}\right) ; 7$ ) pregnancy.

Twelve patients were planned to be enrolled. This number was chosen in order to enhance fast accrual while not compromising the interpretation of the primary endpoint. Primary endpoint was feasibility measured by participation in training sessions as recorded by the supervising physiotherapist. The pragmatic predetermined goal was that $>50 \%$ of patients would attend at least 25 of 36 training sessions. This corresponds to at least twice weekly attendance, which is considered a minimum frequency if the goal is maximizing muscle growth. ${ }^{22}$

Secondary endpoints were changes in functional performance, muscle strength, body composition, adverse events, dietary intake, self-reported physical activity, and QoL as well as investigation of biological samples.

Muscle biopsies were taken for proteomic analyses and blood samples for further analysis as described below.

Evaluation time schedule is shown in Supplementary Table S1.

\section{Treatment}

All patients received CCRT, 66-68 Gy, in 2 Gy fractions, 6 fractions/week, with concurrent nimorazole p.o. $\left(1,200 \mathrm{mg} / \mathrm{m}^{2}\right)^{23}$ before each fraction $\left(1,000 \mathrm{mg} / \mathrm{m}^{2}\right.$ for same-day second fractionation), and weekly cisplatin $\left(40 \mathrm{mg} / \mathrm{m}^{2}\right.$, max $\left.70 \mathrm{mg}\right)$. Prophylactic anti-emetics were administered perorally. Prednisolone:
$100 \mathrm{mg}$ before cisplatin (day 1), $50 \mathrm{mg}$ twice day $2,25 \mathrm{mg}$ twice day 3 , and once day 4. Ondansetron: $16 \mathrm{mg}$ day 1 (if body weight $>80 \mathrm{~kg}$, then $24 \mathrm{mg}$ ) and domperidone $10-20 \mathrm{mg}$ as needed maximally thrice daily.

Physiological saline $(1,500 \mathrm{ml})$ and $8 \mathrm{mmol}$ magnesium sulfate was co-administered with cisplatin. Magnesium $360 \mathrm{mg}$ twice daily p.o. was administered the 3 following days.

If needed, the patients received nasogastric tube feeding. The standard of care in the unit is to offer nasogastric tube feeding if weight loss exceeds approximately 5\% from baseline (treatment start). Routine Percutaneous Endoscopic Gastrostomy (PEG) is not considered standard of care at our unit.

\section{Progressive Resistance Training Program}

The progressive resistance training (PRT) program was almost identical to the program used in the DAHANCA 25 tri$\mathrm{als}^{24}$ and the progression model was based on guidelines from the American College of Sports Medicine (ACSM). ${ }^{25}$ Exercises were performed in training machines (Technogym) and supervised by a physiotherapist. Patients performed 7 conventional exercises involving the large muscle groups (abdominal crunches, back extensions, chest press, low row, hamstring curls, knee extensions, and leg press). Progression in intensity was achieved by patients advancing from $2-3$ sets and $15-8$ repetition maximum (RM), hence, starting with low load/high repetition progressing to high load/fewer repetitions per set (Supplementary Table S2). PRT started concurrently with CCRT. Thirty-six sessions were planned over 12 weeks with sessions thrice weekly, every other weekday to ensure optimal recovery time. After training sessions, patients were offered a meal and protein supplement (Nutridrink compact, Nutricia, $125 \mathrm{~mL}, 1260 \mathrm{~kJ}, 12 \mathrm{~g}$ protein). Patients trained at the physical rehabilitation therapy facilities at the hospital. Training, tests, meals, chemo-, and radiotherapy were scheduled conveniently within the given time frame (Supplementary Table S1).

\section{Functional Performance and Strength Tests}

Tests were supervised by physiotherapists. Functional performance was assessed by maximal stair climbing, 30-second chair stand test, and 30-second arm curl test (respectively 3 and $4 \mathrm{~kg}$ for women and men). These accepted methods have been used previously in cancer patients. ${ }^{24}$ Muscle strength and power were evaluated with reliable and validated tests; the 1repetition maximum (1RM) test in the leg and chest press machines and the Nottingham Power Rig testing maximal leg extension power. ${ }^{26}$

\section{Body Composition}

Changes in total body mass (TBM), LBM, and fat mass (FM) was measured using whole-body Dual-energy X-ray Absorptiometry (DXA) (GE lunar iDXA, GE Healthcare Technologies, Madison, Wisconsin, US), software version 14.10. DXA-scan is a standard and validated method to assess body composition. ${ }^{27}$

Weight was measured weekly (digital scale) with participants in light clothing, without shoes.

\section{Blood Samples}

Standard blood samples, e.g., hematology, prior to each chemotherapy treatment were taken according to schedule (Supplementary Table S1).

Only $36 \mathrm{~mL}$ of additional blood for analysis were drawn during the course of radiotherapy. From baseline until 13months follow-up maximally $336 \mathrm{~mL}$ of blood were drawn for 
explorative biological analyses. At week 3 and 8-12, blood samples were drawn both before and immediately after PRT.

\section{Muscle Biopsies and Proteomic Evaluation}

Muscle biopsies were collected from the vastus lateralis muscle with a $5 \mathrm{~mm}$ Bergstrom biopsy cannula (Pelomi Medical) at baseline, after CCRT, and after the 12-week PRT program under local anesthesia (lidocaine/epinephrine $20 \mathrm{mg} / 5 \mu \mathrm{g} /$ $\mathrm{mL})$.

Mass spectrometry based proteome analysis of skeletal muscle lysate was conducted. Muscle biopsies from the 4 patients with the greatest difference in LBM over the 12 -week training program were analyzed. Protein lysate containing 100 $\mu \mathrm{g}$ of proteins was processed on 30k filtration units using the FASP protocol, ${ }^{28}$ and endoproteinase Lys-C and trypsin were used for the digestion of proteins. Digested peptides were separated on a reverse phase column $(20 \mathrm{~cm}, 75 \mu \mathrm{m}$ inner diameter $)$ packed with $1.8 \mu \mathrm{m}$ C18 particles (Dr. Maisch $\mathrm{GmbH}$, Ammerbuch-Entringen, Germany) using a $3 \mathrm{~h}$ acetonitrile gradient in $0.1 \%$ formic acid at a flow rate of $250 \mathrm{~nL} / \mathrm{min}$. The column was coupled to a Q Exactive mass spectrometer (Thermo Fisher Scientific, Dreieich, Germany) via a nanoelectrospray source (Proxeon Biosystems, now Thermo Fisher Scientific). The $\mathrm{Q}$ Exactive was operated in data dependent mode with survey scans acquired at a resolution of 60,000 . From a survey scan, the top 15 most abundant isotope patterns with charge $\mathrm{m} / \mathrm{z} 2$ were selected with an isolation window of $1.6 \mathrm{Th}$ and fragmented by HCD with normalized collision energies of 27 . The maximum ion injection times for the survey scan and the MS/ MS scans were $20 \mathrm{~ms}$ and $25 \mathrm{~ms}$, respectively. The mass spectrometry data was analyzed in MaxQuant environment (version 1.5.2.8) ${ }^{29}$ Proteins were identified by searching MS and MS/MS data of peptides against a decoy version of the UniProtKB/ Swiss-Prot. Carbamidomethylation of cysteines was set as a fixed modification. The initial allowed mass deviation of the precursor ion was up to $6 \mathrm{ppm}$, and for the fragment masses up to $20 \mathrm{ppm}$. The maximum false peptide discovery rate was specified as 0.01 . Protein concentrations ( $\mathrm{pmol} / \mathrm{mg}$ of proteins) were calculated as previously described. ${ }^{30}$ For further analyses baseline values were set to 1.0 and the following normalized accordingly.

The muscle fiber characterization was determined based on gene expression of the respective gene, i.e., type 1 fibers (myosin heavy chain [MYH] 7 gene), type 2a (MYH2 gene), type $2 \mathrm{x}$ (MYH1 gene), and type 2b (MYH4 gene). Fiber types and the thick and thin filament, $\mathrm{M}$ and Z-band values are presented as median and quartiles of the comprised proteins, whilst for the sarcomeric proteins the individual values as well as medians are presented.

The metabolic pathways were assessed based on protein expression of enzymes from the respective pathways. Hence, glycolysis was assessed by expression of the following enzymes: Hexokinase 1 (HK1 gene), glucose-6-phospate isomerase (GPI gene), 3 phosphofructokinase (PFK) isoenzymes (PFKM, PFKL, and PFKP genes), 2 aldolase isoenzymes (ALDOA and ALDOC genes), triosephosphate isomerase 1 (TPI1 gene), glyceraldehyde-3-phosphate dehydrogenase (GADPH gene), phosphoglycerate kinase 1 (PGK1 gene), phosphoglycerate mutase 2 (PGAM2 gene), 2 enolase isoenzymes (ENO1 and ENO3 genes), and pyruvate kinase (PKM gene). The pentose phosphate pathway (PPP) was assessed by expression of the following enzymes: 6-phosphogluconolactonase (PGLS gene), phosphogluconate dehydrogenase (PGD gene), transketolase (TKT gene) and transaldolase 1 (TALDO1). The medians and upper quartiles of the comprised enzymes for the respective pathway are presented.

\section{Adverse Events Reporting}

Adverse events were monitored according to Common Terminology Criteria for Adverse Events (CTCAE) v4.0.

Performance status was registered according to ECOG scale, and pain using the Numeric Rating Scale (NRS) for pain, consisting of 11 points from 0 (no pain) to 10 (worst pain imaginable). ${ }^{31}$

\section{Questionnaires}

Quality of life questionnaires. QoL was measured by The European Organization for Research and Treatment of Cancer Quality of Life Questionnaire C30 and H\&N35 (EORTC QLQ-C30 and QLQ-H\&N35). The EORTC QLQ-C30 and H\&N35 together consist of global health status, 5 functional scales (physical, role, cognitive, emotional, and social functioning), 10 symptom scales, and 12 individual items. ${ }^{32}$ QoL questionnaires were not done at the end of CCRT, as QoL measurements would be affected by treatment side effects at this time point.

Diet. Energy intake was measured using diet diaries. Resting metabolic rate (RMR) was measured using the Mifflin-St. Jeor equation. ${ }^{33}$ Total energy need in kilojoule (kJ) was measured as: Energy need $(\mathrm{kJ})=\mathrm{RMR} \times$ activity factor $\mathrm{x} 4.184$. Activity factor was set at 1.3 in case of low physical activity, and 1.5 if high physical activity (see below) and set at 1.3 after treatment for all. Protein need was estimated as $18 \%$ of total energy need.

Physical activity. Physical activity during leisure time and work was registered by questionnaire using 4 levels in each category: Leisure time: 1) sedentary, 2) light physical activity 24 hours a week, 3) light physical activity more than 4 hours a week, 4) hard physical activity more than 4 hours a week. Work time: 1) sedentary (e.g., office work), 2) light work (e.g., clerk or teacher), 3) heavier work (e.g., nurse or postman), 4) hard physical work (e.g., concrete worker). Scores were added and dichotomized at $\leq 4$ (low physical activity) or $\geq 5$ (high physical activity).

Questionnaires about the program and affiliation to labor market. At the end of the 12-week PRT program patients were asked to fill out a semi-structured questionnaire regarding the intervention. Affiliation to labor market was registered.

\section{Statistics}

For all statistical analyses, SPSS (IBM Corporation, Armonk, New York, US, https://www.ibm.com/us-en/market place/spss-statistics) 22.0 was used. Descriptive analysis was used for the primary endpoint as well as for all other analyses unless stated otherwise. Mixed-model analyses were used to examine differences in means in body composition and in physical tests between baseline and end of CCRT, after the 12-week PRT, and at 13-month follow-up, respectively. Bonferroni-Holm corrections were made to correct for multiple comparisons. In general, data were normally distributed, tested with ShapiroWilks test, hence, unless otherwise stated values are presented as mean \pm standard deviation (SD).

Spearman's test was used to assess correlation between self-reported physical activity and performance during tests, as well as between baseline BMI and loss of, respectively, TBM, LBM, and FM at 12 weeks. The latter is presented with Spearman's rho and statistical significance.

Repeated measures mixed model analyses were used to examine training progression which is presented as mean $\mathrm{kg}$ 


\begin{tabular}{|c|c|}
\hline \multicolumn{2}{|c|}{$\begin{array}{c}\text { TABLE I. } \\
\text { Patient Baseline Characteristics. }\end{array}$} \\
\hline Characteristics & No. of patients (\%) \\
\hline Patients included & 12 \\
\hline Age, median years (range) & $56(47-66)$ \\
\hline \multicolumn{2}{|l|}{ Sex } \\
\hline male/female & 7 (58\%)/5 (42\%) \\
\hline \multicolumn{2}{|l|}{ Primary site } \\
\hline oropharynx/cancer of the tonsils & $12(100 \%) / 6(50 \%)$ \\
\hline \multicolumn{2}{|l|}{ Tumor p16 status } \\
\hline positive/negative & $12(100 \%) / 0(0 \%)$ \\
\hline \multicolumn{2}{|l|}{ Clinical stage } \\
\hline III/IVa & $1(8 \%) / 11(92 \%)$ \\
\hline \multicolumn{2}{|l|}{ Performance status (ECOG scale) } \\
\hline $0 / 1$ & $12(100 \%) / 0(\%)$ \\
\hline \multicolumn{2}{|l|}{ Smoking status } \\
\hline Never & $3(25 \%)$ \\
\hline Former & $7(58 \%)$ \\
\hline Current & $2(17 \%)$ \\
\hline \multicolumn{2}{|l|}{ Level of physical activity at baseline } \\
\hline low/high & 7 (58\%)/5 (42\%) \\
\hline \multicolumn{2}{|l|}{ BMI } \\
\hline $\mathrm{BMI} \geq 30$ & $3(25 \%)$ \\
\hline BMI 25.0-29.9 & $6(50 \%)$ \\
\hline $\mathrm{BMl}<25$ & $3(25 \%)$ \\
\hline \multicolumn{2}{|l|}{ Charlson Comorbidity score } \\
\hline index score of 0 & $9(75 \%)$ \\
\hline index score of 1 & $3(25 \%)$ \\
\hline \multicolumn{2}{|l|}{ Agreed to muscle biopsies } \\
\hline yes/no & $8(67 \%) / 4(33 \%)$ \\
\hline $\begin{array}{l}\text { Days from diagnosis to radiotherap } \\
\text { mean (range) }\end{array}$ & $21(12-29)$ \\
\hline $\begin{array}{l}\text { Days from diagnosis to training star } \\
\text { mean (range) }\end{array}$ & $23(16-34)$ \\
\hline
\end{tabular}
Group.

$\mathrm{BMI}=$ body mass index; $\mathrm{ECOG}=$ Eastern Cooperative Oncology

load at each of the seven exercises. Only attending patients' data were included in the analyses.

Quality of life data was descriptive and analyzed according to EORTC QLQ-C30 Scoring Manual ${ }^{34}$ and presented as median with range, further statistical analyses were not performed.

For all analyses an alpha level of 5\% was chosen for statistical significance.

\section{RESULTS}

\section{Inclusion}

From February 2014 to July 2014, 24 patients were screened for eligibility. It should be noted that due to capacity challenges in the radiotherapy department there was a 5-week inclusion break. Five patients did not meet inclusion criteria and 19 were informed about the program. Six declined to participate and one was not included due to dysregulated diabetes. Accordingly, 12 patients $(63 \%)$ were included. Though not an inclusion criterion, all patients had p16 positive oropharyngeal cancer. Flow diagram is seen in Supplementary Figure S1 and patients' baseline characteristics are listed in Table I.

No patients withdrew from the study but 2 patients went off study before the 5-month follow-up due to diagnosis of metastatic disease, respectively new primary cancer. Hence, 10 patients completed 13 months of follow-up.

\section{Feasibility}

The primary endpoint was met as $75 \%$ of patients completed at least 25 of 36 training sessions (Fig. 1). Mean completion time for the program was 12.7 weeks (range 11.7-13.7 weeks). Mean attendance rate during treatment was 93\% (range 67-100\%), and overall attendance during the 12 -week program was $77 \pm 22 \%$ (range 36-100\%). Main reason for not attending sessions was treatment-related side effects. No adverse events were deemed related to PRT.

\section{Treatment Completion}

All patients completed full-dose radiotherapy. Ten patients received all 5 planned cisplatin treatments, and 2 patients received only 4 (one due to leukopenia and one due to hearing loss).

\section{Functional Performance and Muscle Strength}

During CCRT, patients' functional performance remained unchanged. After the treatment period, functional performance tended to increase continuously, and at the 13-month follow-up number of arm curls and chair stands had increased significantly compared to baseline ( $p<0.01$ and $p<0.001$, respectively) (Fig. 2 and Supplementary Table S3). It should be noted, that 3 patients felt too weak to be tested immediately after the treatment period (week 6).

Strength as measured by 1RM in chest press decreased significantly $(p<0.01)$ while strength measured in leg press machine remained unchanged, albeit with a lower measured strength just after the CCRT. Large differences were observed between males and females (Fig. 2), whether these were statistically significant differences was not investigated. After the treatment period, strength tended to improve continuously, though, never reaching statistical significance, e.g., 1RM in leg press machine increased from a mean of $144.4 \pm$ $41.6 \mathrm{~kg}$ to a mean of $182.0 \pm 63.2 \mathrm{~kg}$ (Fig. 2 and Supplementary Table S3). Not surprisingly, muscle power, i.e., force produced per $\mathrm{kg}$ body mass, followed the same pattern as muscle strength (Fig. 2E), though not changing significantly from baseline at any time point.

Regarding training intensity (i.e., weight lifted), patients were able to progress in all exercises except chest presses during the 12 -week program $(p<0.05)$ (Fig. 2F).

\section{Body Composition}

All patients experienced weight loss during CCRT. Measurements from the weekly weighing showed that 


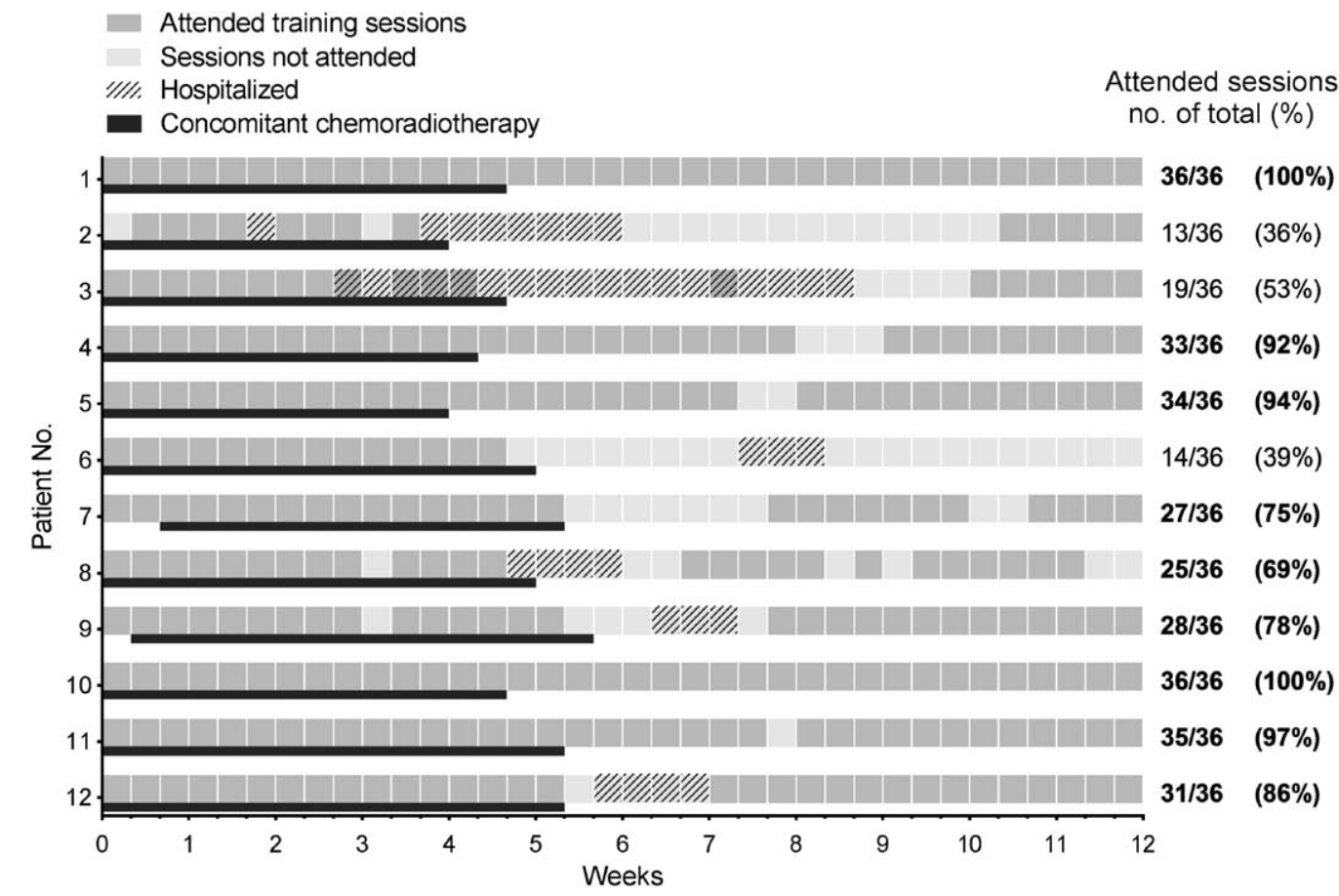

Fig. 1. Attended training sessions per patient. Each dark grey box represents one attended training session. Light grey boxes show sessions not attended, whilst the cross-hatched boxes show when patients were hospitalized. Black lines show the period where each patient was undergoing concomitant chemoradiotherapy during the training program. Right column shows number of attended sessions for each patient, and bold writing when the patient attended at least 25 of 36 planned sessions. Sessions cancelled due to e.g., bank holidays were rescheduled. Sessions missed for personal reasons were not.
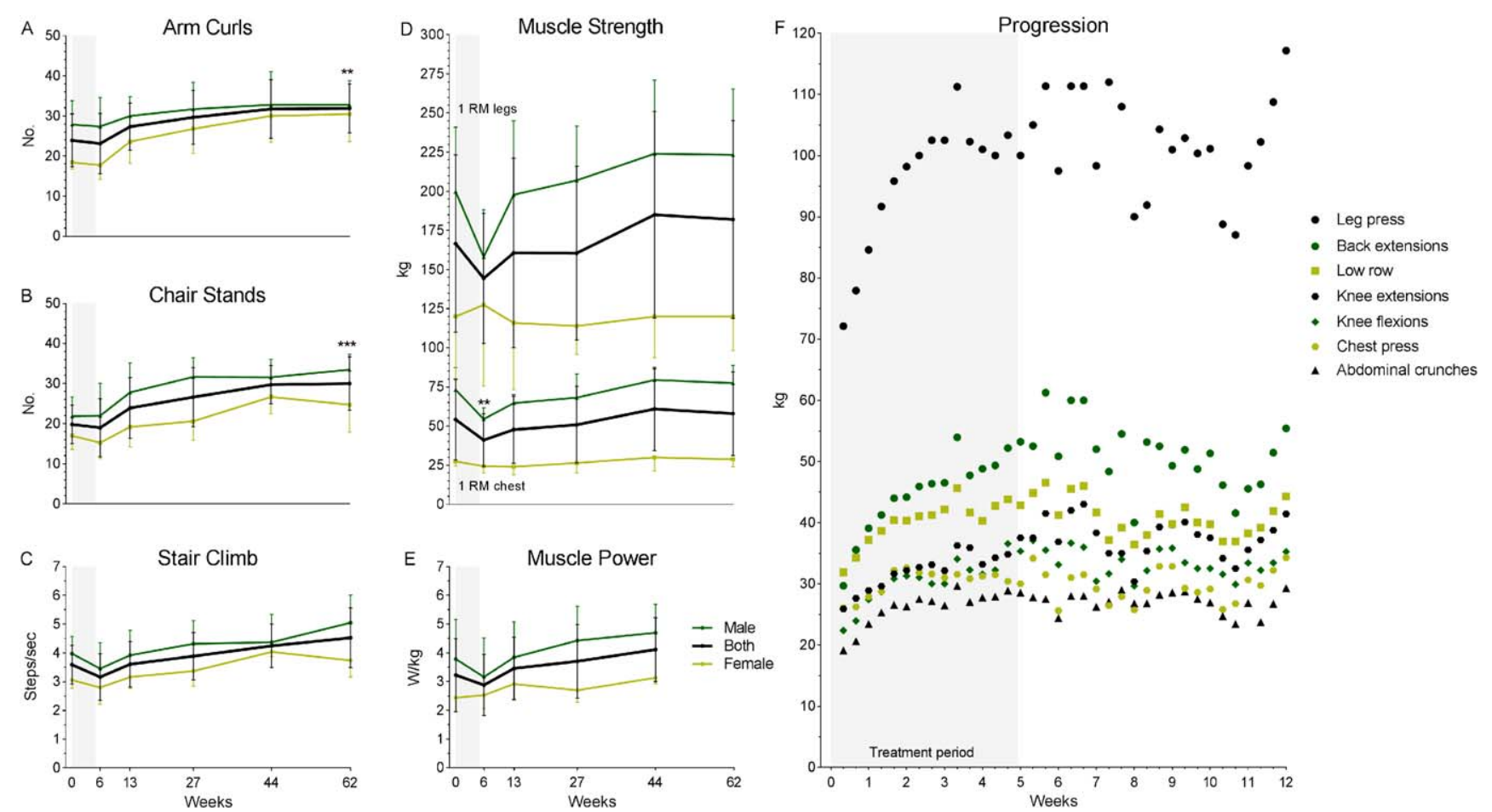

Fig. 2. Physical tests and progression. Functional performance measured by 30 -second arm curl test (A), 30-second chair stand test (B), and stair climbing time (C). Muscle strength measured by 1RM tests in legs and chest press machines, respectively upper and lower part of graph (D), and maximal leg extension power (E). Progression of load (weight lifted) for each exercise (leg press, back extensions, low row, knee extensions, knee flexions, chest press, and abdominal crunches) during the 12-week program (F). A-E: Values presented as mean \pm SD. Change from baseline: ${ }^{* *} p<0.01,{ }^{* \star *} p<0.001$. Black line, both male and female. Dark green line, male. Light green line, female. F: Progression presented as mean values at each training session. Grey area shows treatment period. 
A
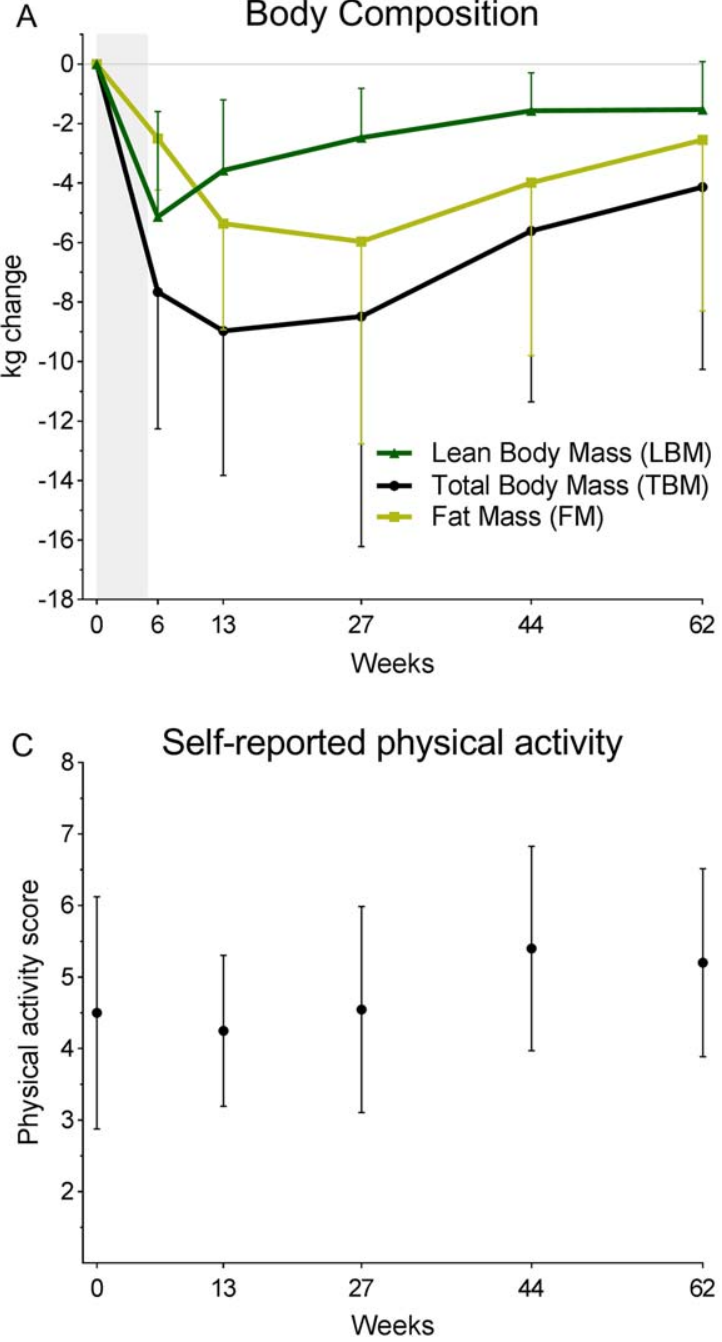

B

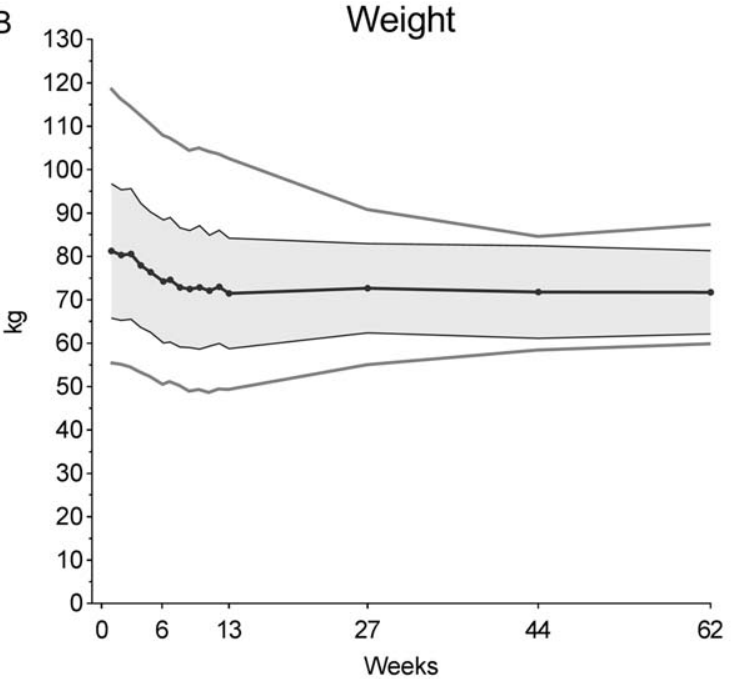

D Composition of TBM loss

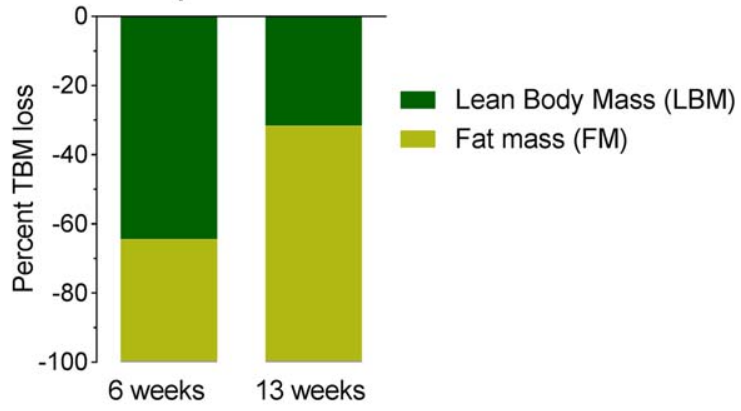

Fig. 3. Body composition, weight, and self-reported physical activity. A. Change in body composition (kg), presented as mean \pm SD. Measured by DXA scan at baseline, after 6 weeks (end of concomitant chemoradiotherapy [CCRT]), after 13 weeks (end of training program), and at 5, 9, and 13-month follow-up (respectively 27, 44, and 62 weeks). Grey area shows treatment period. After CCRT, lean body mass (LBM) began to increase, whilst fat mass (FM) continued to decline during the 12-week training program. At 13-month follow-up total body mass (TBM), LBM, and FM had nearly reached baseline values. Change from baseline: ${ }^{* *} p<0.01,{ }^{* * *} p<0.001$ (significance level was not analyzed at 5 and 9 months follow-up). B. Major weight loss is seen over the course of CCRT (0-6 weeks) and a continued minor loss after CCRT. Lowest mean weight is seen at the end of the progressive resistance training program (13 weeks). Dark grey line shows mean values, colored area shows \pm SD, and light grey line shows the range. C. Scores from leisure time and work were added and presented as mean $\pm S D$. When added a score from 2 to 8 was given; 2 being sedentary throughout the day, 8 being hard physical activity both at work and during leisure time. D. Difference in composition of TBM. At the end of CCRT (week 6) the majority of TBM loss constituted of LBM loss (64\%), while at the end of the 12-week progressive resistance training (PRT) only 32\% of TBM loss was accounted for by LBM.

the weight loss began immediately after the start of treatment and weight declined steadily during the 6 weeks of treatment (Fig. 3B). This seemingly steady decline masks major variance between the patients (Supplementary Table S4). Mean loss of TBM at 6 weeks was $7.7 \pm 4.6 \mathrm{~kg}$ (range 1.9 to 15.6$)(p<0.001)$, equivalent to $9.1 \pm 4.8 \%$ (range 3.6 to 17.5$)(p<0.001)$. Most patients continued losing weight during the training intervention period, though not at the same speed as during treatment. At the 13-week assessment, mean TBM loss was $9.0 \pm 4.9 \mathrm{~kg}$ (range -2.1 to 16.4$)(p<0.001)$, equivalent to $10.8 \pm 5.1 \%$ (range -3.2 to 18.7$)(p<0.001)$. TBM loss peaked at the 13-week assessment but by the 13-month follow-up TBM was partly regained and not significantly different from baseline (Fig. 3A and Supplementary Table S4).

Interestingly, the majority of TBM loss during CCRT comprised of LBM loss $(64 \%)$ while at the end of the 12-week PRT only $32 \%$ of TBM loss was accounted for by LBM (Figure 3D). Thus, LBM loss during CCRT was $5.1 \pm 3.5 \mathrm{~kg}$ (range -0.3 to 11.4$)(p<0.001)$, equivalent to $9.3 \pm 5.6 \%$ (range -0.8 to 20.0$)(p<0.001)$. At this time point LBM was at its lowest and patients began regaining LBM, hence the loss of LBM had decreased and the LBM loss at the 12-week assessment was just $3.6 \pm 2.4 \mathrm{~kg}$ (range 0.7 to 8.0$)(p<0.01)$, equivalent to $6.8 \pm 3.4 \%$ (range 1.4 to 12.3$)(p<0.001)$ (Fig. 3A and Supplementary Table S4). 


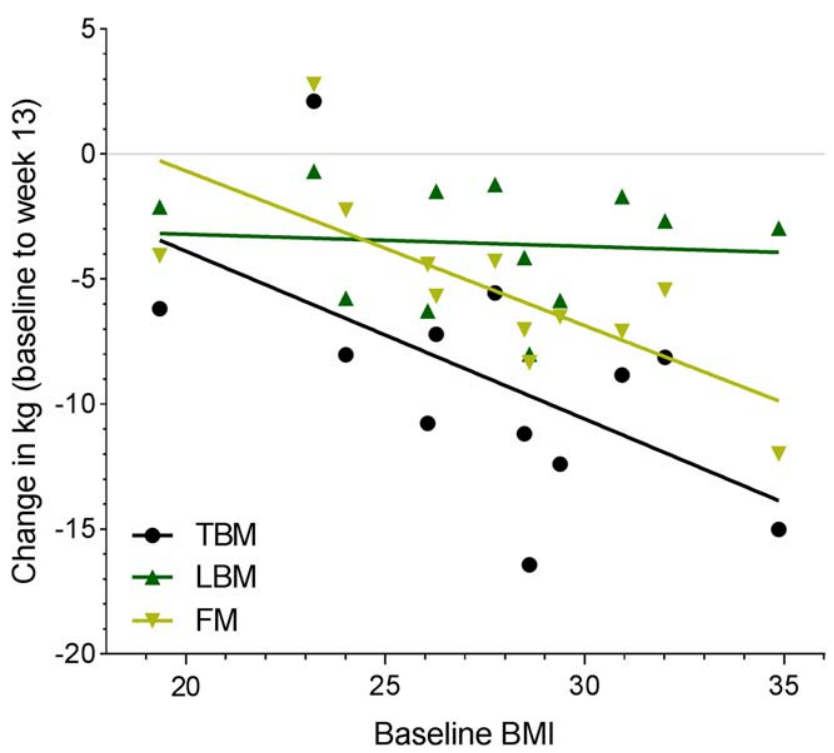

Fig. 4. Correlation between BMI and loss of body mass. The correlation between baseline $\mathrm{BMI}$ and loss of total body mass (TBM), lean body mass (LBM), and fat mass (FM), respectively, after 12 weeks. Data is presented with the individual data as well as an approximated best fitted line for visual interpretation. Baseline BMI was correlated with loss of TBM $\left(r_{s}=0.66 ; p<0.001\right)$ and FM $\left(r_{s}=0.81 ; p<0.001\right)$, respectively, thus, patients with the highest baseline BMI lost the most. There was no correlation between baseline BMI and loss of LBM.

For FM measurements please see Supplementary Table S4 and Figure 3A.

Baseline BMI was correlated with absolute TBM loss at all time points. This correlation was stronger at 13-months follow-up, $r_{s}=0.89, p<0.001$, but evident from the 13-week assessment, $r_{s}=0.66, p=0.01$. There was also a positive correlation between baseline BMI and FM loss at 13 weeks, $r_{s} r=0.81, p<0.01$, as well as at 5 and 13 months follow-up, $r_{s}=0.81, p<0.001$, $r=0.85, p<0.01$, respectively. There was no correlation between baseline BMI and absolute LBM loss at any time point. Data from the 13 -week assessment, i.e. after the training intervention, is shown in Figure 4.

\section{Muscle Biopsies}

In line with the loss of LBM during CCRT, the protein abundance of sarcomeric proteins tended to decrease during CCRT and then increase during the 12week PRT intervention period (not statistically significant) (Fig. 5). The same pattern was seen in the different types of myosin isoforms, i.e., Myosin Heavy Chain (MyHC)-Slow (slow contraction time, low power), MyHC2a (moderately fast contraction time, medium power), MyHC-2x (fast contraction time, high power), and MyHC-2b (very fast contraction time, very high power) (Fig. 6B). Interestingly, enzymes from the pentose phosphate pathway (PPP) tended to be up-regulated at week 6 compared to baseline $(p<0.01)$ whilst the glycolysis pathway remained unchanged (Fig. 6A).

\section{Blood Biochemistry}

Hemoglobin, leukocytes, platelets, and plasma ions showed characteristic changes during and after CCRT (Supplementary Fig. S2). Plasma glucose increased significantly over the course of treatment and dropped to baseline values around 2-month follow-up.

\section{Adverse Events}

Treatment-related toxicities were as expected during and after treatment (Table II). Most frequent treatment-related toxicity reported was mucositis, reported by all patients, $50 \%$ with grade 3 . Fatigue was also reported by all patients, though no grade 3 or 4 events. $92 \%$ of patients experienced nausea, $17 \%$ grade 3 and no grade 4. As time passed, toxicity seemed to decline though not quite matching baseline values at 9 months. No serious adverse events were deemed related to PRT.

Six patients were admitted to hospital due to treatment complications, 3 during the treatment period, and the others in the weeks following treatment; median time of admission was 8 days (range 5-36). Reasons for hospitalization were nutritional problems as a consequence of pain from the irradiated mucosa. Furthermore, 3 patients were prescribed antibiotics due to neutropenia and/or fever.

Seven patients needed a nasogastric tube for a median duration of 33 days (range 12-75).

\section{Questionaires}

Quality of life. Global health status, emotional, cognitive, and social functioning all appeared to decline during the 12-week program and return to baseline values at 5-month follow-up, but noticeably, only minor changes were reported regarding physical and role functioning (Supplementary Fig. S3). It should be noted, that no comparisons of means or change over time analyses were performed.

Diet. Overall, patients reported marginally insufficient total energy intake compared to estimated needs (78-98\%) (Supplementary Table S4). Likewise, protein intake ranged from $64-90 \%$ of estimated need, however return of questionnaires on dietary intake was low $(50 \%)$.

Patient reported physical activity, labor market affiliation and opinions on the PRT program. Self-reported physical activity showed no significant variation over 13 months (Fig. 3C). A positive correlation between self-reported physical activity and functional performance $(p<0.05)$, and muscle strength $(p<0.05)$, respectively, was observed.

At baseline, 8 patients worked full time, 3 part time, and 1 had retired. During treatment and at 2month follow-up all patients were on full or part-time sick leave, but at 5-month follow-up 8 patients were working, 4 of which worked full time. At 9-month followup 8 of the remaining 10 patients had returned to work, 5 at full time. At the 13-month follow-up 9 patients had returned to work, 6 at full time. 


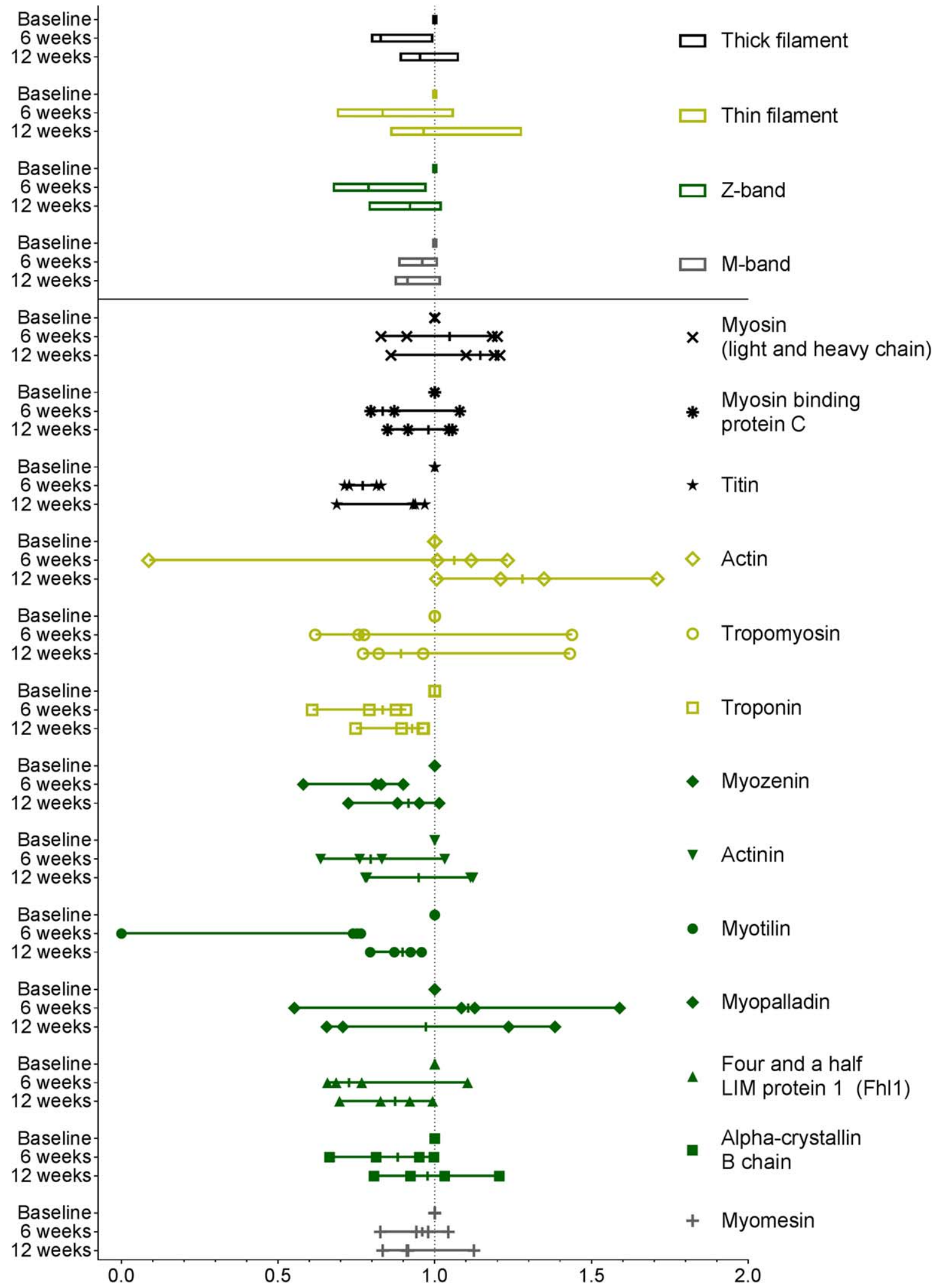

Fig. 5. Sarcomeric protein content in muscle. Baseline values are set to 1.0, and values are normalized accordingly. Thick filament consists of myosin, myosin binding protein $\mathrm{C}$, and titin; thin filament of actin, tropomyosin, and troponin; Z-band of myozenin, actinin, myotilin, myopalladin, Fhl1, and alpha-crystallin B chain; and M-band of myomesin. Protein abundance of sarcomeric proteins tends to decrease during CCRT and increase after the 12 weeks of resistance training. 

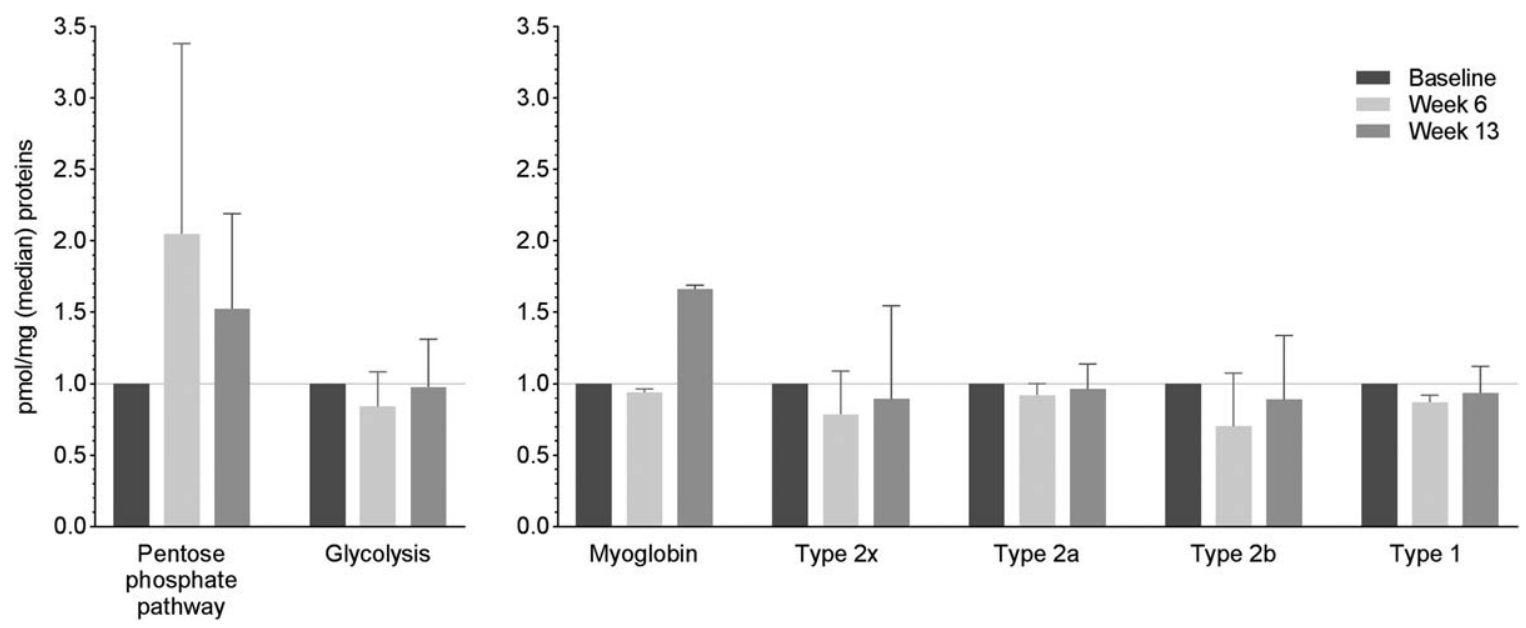

Fig. 6. Metabolic pathways, myoglobin, and muscle fiber types. Muscle biopsies from the four patients with the greatest difference in lean body mass during the 12 weeks of progressive resistance training (PRT) were analyzed using mass spectrometry based proteome analysis. A. Change in enzyme expression in the pentose phosphate pathway (PPP) and glycolysis. Enzymes from the PPP seemed to be upregulated at week 6 compared to baseline whilst the glycolysis pathway remained unchanged. B. Changes in myoglobin and the fiber types of skeletal muscle were investigated. Type 1 (slow contraction time, low power), type 2a (moderately fast contraction time, medium power), and type $2 \mathrm{x}$ (fast contraction time, high power), and type $2 \mathrm{~b}$ (very fast contraction time, very high power). A+B. Baseline values are set to 1.0 and values at week 6 and 13 are normalized accordingly. Median values and upper quartiles are presented.

At the end of the 12-week PRT program patients were asked several open-labeled questions regarding their participation in the program. In general, patients were satisfied with the program and the time schedule.
They reported large benefits regarding social, physical, and psychological well-being, and generally recommended the program for future patients. Patients stated for example that "this has been a lifesaver", "made going

\begin{tabular}{|c|c|c|c|c|c|c|c|c|c|c|c|c|c|c|}
\hline \multicolumn{15}{|c|}{$\begin{array}{l}\text { TABLE II. } \\
\text { Toxicity. }\end{array}$} \\
\hline & \multicolumn{2}{|c|}{$\begin{array}{l}\text { Baseline } \\
(n=12)\end{array}$} & \multicolumn{2}{|c|}{$\begin{array}{l}\text { During treatment } \\
\qquad(\mathrm{n}=12)\end{array}$} & \multicolumn{2}{|c|}{$\begin{array}{c}14 \text { days post } \\
\text { CCRT } \\
(n=12)\end{array}$} & \multicolumn{2}{|c|}{$\begin{array}{c}2 \text { months post } \\
\text { CCRT } \\
(\mathrm{n}=12)\end{array}$} & \multicolumn{2}{|c|}{$\begin{array}{c}5 \text { months post } \\
\text { CCRT } \\
(n=12)\end{array}$} & \multicolumn{2}{|c|}{$\begin{array}{c}9 \text { months post } \\
\text { CCRT } \\
(n=10)\end{array}$} & \multicolumn{2}{|c|}{$\begin{array}{c}13 \text { months post } \\
\text { CCRT } \\
(n=10)\end{array}$} \\
\hline & $\begin{array}{l}\text { Any } \\
\text { grade } \\
(\%)\end{array}$ & $\begin{array}{c}\% \\
3 \text { and } 4\end{array}$ & $\begin{array}{l}\text { Any } \\
\text { grade } \\
(\%)\end{array}$ & $\begin{array}{c}\% \\
3 \text { and } 4\end{array}$ & $\begin{array}{l}\text { Any } \\
\text { grade } \\
(\%)\end{array}$ & $\begin{array}{c}\% \\
3 \text { and } 4\end{array}$ & $\begin{array}{l}\text { Any } \\
\text { grade } \\
(\%)\end{array}$ & $\begin{array}{c}\% \\
3 \text { and } 4\end{array}$ & $\begin{array}{l}\text { Any } \\
\text { grade } \\
(\%)\end{array}$ & $\begin{array}{c}\% \\
3 \text { and } 4\end{array}$ & $\begin{array}{l}\text { Any } \\
\text { grade } \\
(\%)\end{array}$ & $\begin{array}{c}\% \\
3 \text { and } 4\end{array}$ & $\begin{array}{l}\text { Any } \\
\text { grade } \\
(\%)\end{array}$ & $\begin{array}{c}\% \\
3 \text { and } 4\end{array}$ \\
\hline PS & 0 & 0 & 75.0 & 0 & 75.0 & 0 & 33.3 & 0 & 8.3 & 0 & 0 & 0 & 0 & 0 \\
\hline Fatigue & 33.3 & 0 & 100.0 & 0 & 100.0 & 0 & 83.3 & 0 & 33.3 & 0 & 20.0 & 0 & 40.0 & 0 \\
\hline Nausea & 0 & 0 & 91.7 & 16.7 & 50.0 & 8.3 & 33.3 & 0 & 0 & 0 & 0 & 0 & 0 & 0 \\
\hline Vomiting & 0 & 0 & 66.7 & 0 & 41.7 & 0 & 0 & 0 & 0 & 0 & 0 & 0 & 0 & 0 \\
\hline Diarrhea & 8.3 & 0 & 16.7 & 0 & 8.3 & 0 & 0 & 0 & 0 & 0 & 0 & 0 & 0 & 0 \\
\hline Mucositis & 0 & 0 & 100.0 & 50.0 & 91.7 & 8.3 & 33.3 & 0 & 16.7 & 0 & 20 & 0 & 10 & 0 \\
\hline Constipation & 0 & 0 & 75.0 & 0 & 41.7 & 0 & 8.3 & 0 & 0 & 0 & 0 & 0 & 0 & 0 \\
\hline Neuropathy (S) & 0 & 0 & 16.7 & 0 & 25.0 & 0 & 16.7 & 0 & 8.3 & 0 & 40.0 & 0 & 10.0 & 0 \\
\hline Neuropathy (M) & 0 & 0 & 8.3 & 0 & 8.3 & 0 & 8.3 & 0 & 0 & 0 & 0 & 0 & 10.0 & 0 \\
\hline Neutropenic fever & 0 & 0 & 0 & 0 & 8.3 & 8.3 & 0 & 0 & 0 & 0 & 0 & 0 & 0 & 0 \\
\hline Fever & 0 & 0 & 0 & 0 & 8.3 & 0 & 0 & 0 & 0 & 0 & 0 & 0 & 0 & 0 \\
\hline Hearing & 8.3 & 0 & 25.0 & 8.3 & 16.7 & 8.3 & 8.3 & 8.3 & 8.3 & 8.3 & 10.0 & 10.0 & 10.0 & 10.0 \\
\hline Pain in throat (\%) & \multicolumn{2}{|c|}{$(n=12)$} & \multicolumn{2}{|c|}{$(n=11)$} & \multicolumn{2}{|c|}{$(n=10)$} & \multicolumn{2}{|c|}{$(n=12)$} & \multicolumn{2}{|c|}{$(n=12)$} & \multicolumn{2}{|c|}{$(n=10)$} & \multicolumn{2}{|c|}{$(n=7)$} \\
\hline - no pain & \multicolumn{2}{|c|}{66.7} & \multicolumn{2}{|c|}{0} & \multicolumn{2}{|c|}{10.0} & \multicolumn{2}{|c|}{66.7} & \multicolumn{2}{|c|}{83.3} & \multicolumn{2}{|c|}{90.0} & \multicolumn{2}{|c|}{85.7} \\
\hline - mild pain & \multicolumn{2}{|c|}{16.7} & \multicolumn{2}{|c|}{0} & \multicolumn{2}{|c|}{40.0} & \multicolumn{2}{|c|}{16.7} & \multicolumn{2}{|c|}{8.3} & \multicolumn{2}{|c|}{10.0} & \multicolumn{2}{|c|}{14.3} \\
\hline - moderate pain & \multicolumn{2}{|c|}{16.7} & \multicolumn{2}{|c|}{9.1} & \multicolumn{2}{|c|}{20.0} & & 3.3 & & .0 & & 0 & & 0 \\
\hline - severe pain & & 0 & & 0.9 & & 0.0 & & 3.3 & & .3 & & 0 & & 0 \\
\hline
\end{tabular}

Toxicities were scored according to CTCAE version 4.0 and were as expected during and after concomitant chemoradiotherapy. NRS pain scores were grouped as follows: 0 , no pain; $1-2$, mild pain; $3-4$, moderate pain; 5-10, severe pain. CTCAE $=$ Common Terminology Criteria for Adverse Events; $M=$ motor. NRS = Numeric Rating Scale; $S=$ sensory. 
through treatment easier", "when I was down and physically exhausted, working out helped me feel better and gave me energy", "the best that could happen in our situation." (Supplementary Table S5).

\section{DISCUSSION}

Progressive resistance training is feasible and appreciated by patients with stage III/IV head and neck cancer undergoing CCRT. In addition to testing the feasibility of the PRT program during treatment, this study included a range of secondary endpoints to test the entire setting of a PRT study, including scans, questionnaires, etc., before launching a randomized trial.

Evaluations of physical activity levels in HNSCC survivors show that very few of these participate in moderate or vigorous exercise, and that more than half of them are sedentary. ${ }^{35}$ Treatment-related symptoms are frequent barriers to exercise training, ${ }^{36}$ as these patients are typically heavily taxed with cumulated treatment toxicity. ${ }^{37}$ Furthermore, following radiotherapy HNSCC survivors show lower levels of LBM, muscle strength, and functional performance compared to healthy individuals. Yet, one study showed that 12 weeks of PRT after treatment completion evened out the differences. $^{38}$ We hypothesized that moving PRT forward, concurrent with treatment, may attenuate the deterioration experienced during treatment and facilitate quicker recovery. A few studies have investigated exercise training in HNSCC patients concurrent with treatment. ${ }^{18-21}$ However, these trials are heterogeneous with regard to several variables such as patient group (radiotherapy treated only, CCRT, or mixed), intervention (type, frequency, and intensity), and outcome measures (e.g., feasibility, QoL, functional performance, fatigue) making them nearly impossible to compare, let alone extend the results and conclude on the feasibility of a different program in another clinical setting. Thus, before launching a larger clinical trial, we decided to conduct a pilot study testing the feasibility of the program.

We found that $68 \%$ (13 out of 19) of eligible patients informed about the protocol accepted inclusion, showing that some patients definitely are interested in conducting exercise during treatment. This was confirmed by an adherence rate during CCRT of $93 \%$. However, as treatment progresses so does treatment side effects, and as a consequence adherence declined during the end of the treatment period and the weeks following, as seen in Figure 1. As adverse events diminished, we found that training attendance increased again. When asked, the patients proclaimed that the training made going through treatment easier, and helped them feel better and more energetic, but an objective evaluation of this was not possible as no control group was included. The patient group is highly selected as only patients with performance status $0-1$ were included, this was predetermined as an inclusion criteria. Furthermore, all patients had p16-positive oropharyngeal cancer, which was not predetermined but a result of the patient population in the unit and maybe also due to positive attitude towards exercise in this head and neck cancer population. Naturally, this limits interpretation of the results to this group of head and neck cancer patients, but as the incidence of HPV-related head and neck cancers is increasing the number of patients for whom these criteria is applicable also increases. ${ }^{39,40}$

A particular concern in head and neck cancer patients is weight loss. Weight loss around 10\% during treatment is not unusual and as much as $72 \%$ is constituted of LBM loss. ${ }^{1,4}$ Since depletion in muscle mass is associated with increased risk of recurrence as well as overall mortality, ${ }^{7}$ finding countermeasures while not compromising safety is crucial. Data from this pilot study does not give rise to any concerns regarding accelerated weight loss, with a mean weight loss of $9 \%$ after treatment at week 6 . On the contrary, while TBM and FM loss continued after end of treatment, patients in this study started gaining LBM immediately after treatment cessation. Whether this was due to PRT is not possible to answer in this non-randomized study. Jackson et al. have presented similar results in a study with a subset of HNSCC patients from a larger cohort. ${ }^{1}$ Data were pooled from controls and exercise patients and also here, the patients regained LBM faster than TBM.

A significant increase in functional performance at the 13-month follow-up was seen. This may be attributed to increased awareness of exercise after attending the PRT program, but may just as likely merely reflect that the patients are disease free and have recovered physically following the cancer diagnosis.

In addition to the gross measure of LBM, we also performed detailed molecular profiling of the muscular sarcomeric protein content. The sarcomers make up the bulk of the muscles, and comprise the contractile units within the muscle fibers. We found that the expression of these sarcomeric proteins followed the pattern of both LBM and muscle strength, indicating that reductions in LBM and muscle strength may rely not only on functional deficits but also on structural changes. In addition, we evaluated expression of the different myosin heavy chain genes. All tended to decrease in line with the loss of muscle mass and sarcomeric protein content. Yet, the effect was most pronounced for type 2, which are also the fiber types, which are most readily affected by physical inactivity and neural denervation. Moreover, studies have shown that resistance training causes a decrease in MyHC-2x expression and an increase in MyHC-2 $a,{ }^{41}$ which might also play a role in our study.

Interestingly, we found the pentose phosphate pathway (PPP) seemed to be up-regulated. PPP is known to play an important part in the anabolic metabolism of the cells and it holds a key part in cell proliferation as it generates ribose-5-phosphate to be used in nucleotides and nucleic acids. ${ }^{42} \mathrm{~A}$ major product from this synthesis is NADPH, which is essential for sequestering intracellular oxidative stress. Thus, this finding might indicate treatment-induced stress of the intramuscular signaling pathways.

Resistance training was chosen as the exercise modality due to superiority to aerobic exercise in inducing muscle hypertrophy. ${ }^{22}$ For optimal hypertrophic 
response progression in training intensity is essential. The data presented here shows that patients did progress during the 12-week training program in terms of weight lifted, even during the treatment period with heavy adverse effects. When designing exercise interventions, it is important to consider essential principles of training, i.e., individualization, specificity, progression, and recovery. ${ }^{43}$ In this study, training was individualized and prescribed relative to baseline muscular strength status. Moreover, training took place at the hospital and was coordinated with meals and treatments, and finally patients trained every other day giving the muscles appropriate resting periods.

The potential benefit of adding PRT to the CCRT program can only be examined in larger and randomized studies. In such studies, not only the nominal LBM change but also changes in strength, functional performance, QoL, adverse events, and dietary intake are relevant in order to determine any potential benefits. This study was merely the necessary pilot study indicating whether a randomized trial may be possible in our clinical setting. However, we can conclude that collecting these data was feasible and the positive responses from the patients definitely support the plan to test progressive resistance training during treatment for head and neck cancer in a randomized controlled trial. ${ }^{44}$

Recently, it was shown that loss of LBM during treatment is associated with increased mortality, ${ }^{7}$ hence, if resistance training can attenuate loss of LBM in these patients it may very well positively affect long-term outcome. That exercise to some extent can be used as medicine in various diseases is beyond any doubt ${ }^{45}$ but to what extent it is possible to change disease outcome in head and neck cancer patients is just one of many questions within the field of exercise-oncology that must be further elucidated.

\section{CONCLUSION}

This article shows that PRT in severely affected patients undergoing CCRT for head and neck cancer is not only feasible, but patients also respond favorably to the training intervention. Of course, only a randomized trial will be able to reveal the potential effect of PRT during CCRT in head and neck cancer patients.

\section{ACKNOWLEDGMENTS}

A special thanks to physiotherapist Anne-Mette Ragle who supervised training sessions and tests; to nurses Pia Poulsen and Jette Ottosen Alsted for patient care and treatment; and to lab technician Marianne Fregil for measurements of cytokines.

\section{BIBLIOGRAPHY}

1. Jackson W, Alexander N, Schipper M, Fig L, Feng F, Jolly S. Characterization of changes in total body composition for patients with head and neck cancer undergoing chemoradiotherapy using dual-energy x-ray absorptiometry. Head Neck 2014;36:1356-1362.

2. Ottosson S, Zackrisson B, Kjellén E, Nilsson P, Laurell G. Weight loss in patients with head and neck cancer during and after conventional and accelerated radiotherapy. Acta Oncol 2013;52:711-718.

3. Platek ME, Myrick E, McCloskey SA, et al. Pretreatment weight status and weight loss among head and neck cancer patients receiving definitive concurrent chemoradiation therapy: implications for nutrition integrated treatment pathways. Support Care Cancer 2013;21:28252833.

4. Silver HJ, Dietrich MS, Murphy BA. Changes in body mass, energy balance, physical function, and inflammatory state in patients with locally advanced head and neck cancer treated with concurrent chemoradiation after low-dose induction chemotherapy. Head Neck 2007;29:893-900.

5. Langius JA, van Dijk AM, Doornaert P, et al. More than $10 \%$ weight loss in head and neck cancer patients during radiotherapy is independently associated with deterioration in quality of life. Nutr Cancer 2013;65:7683.

6. Meyer F, Fortin A, Wang CS, Liu G, Bairati I. Predictors of severe acute and late toxicities in patients with localized head-and-neck cancer treated with radiation therapy. Int J Radiat Oncol Biol Phys 2012;82: 1454-1462.

7. Grossberg AJ, Chamchod S, Fuller CD, et al. Association of body composition with survival and locoregional control of radiotherapy-treated head and neck squamous cell carcinoma. JAMA Oncol 2016;2:782-789.

8. Ghadjar P, Simcock M, Zimmermann F, et al. Predictors of severe late radiotherapy-related toxicity after hyperfractionated radiotherapy with or without concomitant cisplatin in locally advanced head and neck cancer. Secondary retrospective analysis of a randomized phase III trial (SAKK 10/94). Radiother Oncol 2012;104:213-218.

9. Capuano G, Grosso A, Gentile PC, et al. Influence of weight loss on outcomes in patients with head and neck cancer undergoing concomitant chemoradiotherapy. Head Neck 2008;30:503-508.

10. Langius JA, Bakker S, Rietveld DH, et al. Critical weight loss is a major prognostic indicator for disease-specific survival in patients with head and neck cancer receiving radiotherapy. Br J Cancer 2013;109:10931099 .

11. Jager-Wittenaar H, Dijkstra PU, Vissink A, et al. Changes in nutritional status and dietary intake during and after head and neck cancer treatment. Head Neck 2011;33:863-870.

12. Brown JC, Winters-Stone K, Lee A, Schmitz KH. Cancer, physical activity, and exercise. Compr Physiol 2012;2:2775-2809.

13. Je Y, Jeon JY, Giovannucci EL, Meyerhardt JA. Association between physical activity and mortality in colorectal cancer: a meta-analysis of prospective cohort studies. Int J Cancer 2013;133:1905-1913.

14. Ibrahim EM, Al-Homaidh A. Physical activity and survival after breast cancer diagnosis: meta-analysis of published studies. Med Oncol 2011; 28:753-765.

15. Pedersen L, Idorn M, Olofsson GH, et al. Voluntary running suppresses tumor growth through epinephrine- and IL-6-dependent NK cell mobilization and redistribution. Cell Metab 2016;23:554-562.

16. Pedersen L, Christensen JF, Hojman P. Effects of exercise on tumor physiology and metabolism. Cancer $J$ 2015;21:111-116.

17. Hojman P, Fjelbye J, Zerahn B, et al. Voluntary exercise prevents cisplatin-induced muscle wasting during chemotherapy in mice. PLoS One 2014;9:e109030.

18. Rogers LQ, Anton PM, Fogleman A, et al. Pilot, randomized trial of resistance exercise during radiation therapy for head and neck cancer. Head Neck 2013;35:1178-1188.

19. Samuel SR, Maiya GA, Babu AS, Vidyasagar MS. Effect of exercise training on functional capacity \& quality of life in head \& neck cancer patients receiving chemoradiotherapy. Indian J Med Res 2013;137:515520 .

20. Zhao SG, Alexander NB, Djuric Z, et al. Maintaining physical activity during head and neck cancer treatment: results of a pilot controlled trial. Head Neck 2016;38(Suppl 1):E1086-1096.

21. Capozzi LC, McNeely ML, Lau HY, et al. Patient-reported outcomes, body composition, and nutrition status in patients with head and neck cancer: results from an exploratory randomized controlled exercise trial. Cancer 2016:122:1185-1200.

22. Schoenfeld BJ, Ogborn D, Krieger JW. Effects of resistance training frequency on measures of muscle hypertrophy: a systematic review and meta-analysis. Sports Med 2016;46:1689-1697.

23. Overgaard J, Hansen HS, Overgaard M, et al. A randomized double-blind phase III study of nimorazole as a hypoxic radiosensitizer of primary radiotherapy in supraglottic larynx and pharynx carcinoma. Results of the Danish Head and Neck Cancer Study (DAHANCA) Protocol 5-85. Radiother Oncol 1998;46:135-146.

24. Lonbro S, Dalgas U, Primdahl H, Overgaard J, Overgaard K. Feasibility and efficacy of progressive resistance training and dietary supplements in radiotherapy treated head and neck cancer patients-the DAHANCA 25A study. Acta Oncol 2013;52:310-318.

25. American College of Sports Medicine position stand. Progression models in resistance training for healthy adults. Med Sci Sports Exerc 2009;41: $687-708$

26. Schroeder ET, Wang Y, Castaneda-Sceppa C, et al. Reliability of maximal voluntary muscle strength and power testing in older men. J Gerontol A Biol Sci Med Sci 2007;62:543-549.

27. Lee SY, Gallagher D. Assessment methods in human body composition. Curr Opin Clin Nutr Metab Care 2008;11:566-572.

28. Wisniewski JR, Zougman A, Mann M. Combination of FASP and StageTipbased fractionation allows in-depth analysis of the hippocampal membrane proteome. J Proteome Res 2009;8:5674-5678.

29. Cox J, Mann M. MaxQuant enables high peptide identification rates, individualized p.p.b.-range mass accuracies and proteome-wide protein quantification. Nat Biotechnol 2008;26:1367-1372. 
30. Rakus D, Gizak A, Deshmukh A, Wisniewski JR. Absolute quantitative profiling of the key metabolic pathways in slow and fast skeletal muscle. $J$ Proteome Res 2015;14:1400-1411.

31. Hawker GA, Mian S, Kendzerska T, French M. Measures of adult pain: Visual Analog Scale for Pain (VAS Pain), Numeric Rating Scale for Pain (NRS Pain), McGill Pain Questionnaire (MPQ), Short-Form McGill Pain Questionnaire (SF-MPQ), Chronic Pain Grade Scale (CPGS), Shor Form-36 Bodily Pain Scale (SF-36 BPS), and Measure of Intermittent and Constant Osteoarthritis Pain (ICOAP). Arthritis Care Res (Hoboken) 2011;63(Suppl 11):S240-S252.

32. Aaronson NK, Ahmedzai S, Bergman B, et al. The European Organization for Research and Treatment of Cancer QLQ-C30: a quality-of-life instrument for use in international clinical trials in oncology. $J$ Natl Cancer Inst 1993;85:365-376.

33. Frankenfield DC. Bias and accuracy of resting metabolic rate equations in non-obese and obese adults. Clin Nutr 2013;32:976-982.

34. Fayers P, Aaronson N, Bjordal K, Groenvold M, Curran D, Bottomley AObotEQoLG. The EORTC QLQ-C30 Scoring Manual (3rd Edition). Brussels: EORTC 2001. Available at: http://www.eortc.be/qol/files/SCMa nualQLQ-C30.pdf.

35. Rogers LQ, Courneya KS, Robbins KT, et al. Physical activity and quality of life in head and neck cancer survivors. Support Care Cancer 2006;14:1012 1019

36. Rogers LQ, Courneya KS, Robbins KT, et al. Physical activity correlates and barriers in head and neck cancer patients. Support Care Cancer 2008;16:19-27.
37. Villa A, Sonis S. Toxicities associated with head and neck cancer treatmen and oncology-related clinical trials. Curr Probl Cancer 2016;40:244-257.

38. Lonbro $\mathrm{S}$, Dalgas $\mathrm{U}$, Primdahl $\mathrm{H}$, et al. Lean body mass and muscle function in head and neck cancer patients and healthy individuals-results from the DAHANCA 25 study. Acta Oncol 2013;52:1543-1551.

39. Chaturvedi AK, Engels EA, Pfeiffer RM, et al. Human papillomavirus and rising oropharyngeal cancer incidence in the United States. $J$ Clin Oncol 2011;29:4294-4301.

40. Garnaes E, Kiss K, Andersen L, et al. A high and increasing HPV prevalence in tonsillar cancers in Eastern Denmark, 2000-2010: the largest registry-based study to date. Int J Cancer 2015;136:2196-2203.

41. Andersen JL, Aagaard P. Effects of strength training on muscle fiber types and size; consequences for athletes training for high-intensity sport. Scand J Med Sci Sports 2010;20(Suppl 2):32-38.

42. Riganti C, Gazzano E, Polimeni M, Aldieri E, Ghigo D. The pentose phosphate pathway: an antioxidant defense and a crossroad in tumor cell fate. Free Radic Biol Med 2012;53:421-436.

43. Sasso JP, Eves ND, Christensen JF, Koelwyn GJ, Scott J, Jones LW. A framework for prescription in exercise-oncology research. $J$ Cachexia Sarcopenia Muscle 2015;6:115-124.

44. Lonkvist CK, Lønbro S, Vinther A, et al. Progerssive resistance training in head and neck cancer patients during concomitant chemoradiotherapy design of the DAHANCA 31 randomized trial. BMC Cancer 2017:17:400.

45. Pedersen BK, Saltin B. Exercise as medicine - evidence for prescribing exercise as therapy in 26 different chronic diseases. Scand J Med Sci Sports 2015;25(Suppl 3):1-72. 